\title{
ERBB2 NM_004448.3:c.2305G>C
}

National Cancer Institute

\section{Source}

National Cancer Institute. ERBB2 NM 004448.3:C.2305G>C. NCI Thesaurus. Code C155301.

A nucleotide substitution at position 2305 of the coding sequence of the ERBB2 gene where guanine has been mutated to cytosine. 